\title{
Bronchial hyperresponsiveness in young students of southern China: relation to respiratory symptoms, diagnosed asthma, and risk factors
}

\author{
N S Zhong, R C Chen, M O-yang, J Y Wu, W X Fu, L J Shi
}

\begin{abstract}
A cross sectional study was carried out to determine the prevalence of bronchial hyperresponsiveness and asthma in 3067 students aged 11-17 years in an urban and a rural area of Guangzhou (Canton), China. The methods used included a self administered questionnaire, a histamine bronchial provocation test, and allergen skinprick tests. Bronchial hyperresponsiveness was defined as a $20 \%$ fall in $\mathrm{FEV}_{1}$ and peak expiratory flow at a provoking dose of histamine $\left(\mathbf{P D}_{20}\right)$ less than $7.8 \mu \mathrm{mol}$ on two occasions four weeks apart. The response rate was $98.0 \%$ and $99.2 \%$ in the two areas. The prevalence of bronchial hyperresponsiveness was $4 \cdot 1 \%$ and of diagnosed asthma $2 \cdot 4 \%$ in the total population. There were no significant differences in prevalence between the urban and the rural area or between boys and girls. The 11-12 year group had a higher prevalence of bronchial hyperresponsiveness $(7 \cdot 6 \%)$ than the older groups. Of the 125 with bronchial hyperresponsiveness, $12.0 \%$ were defined as having severe or moderate $\left(\mathbf{P D}_{20}<0.8 \mu \mathrm{mol}\right), 26 \%$ mild (0.9-3.2 $\mu \mathrm{mol})$, and $62 \%$ slight bronchial hyperresponsiveness (3.3-7.8 $\mu \mathrm{mol})$. The severity of bronchial hyperresponsiveness was closely related to diagnosed asthma, wheezing, and cough, though half the students with bronchial hyperresponsiveness were symptom free. The most common allergens were house dust and house dust mite in the city, and hay dust, pollen, and feathers in the rural area. The odds ratios for having respectively slight, mild or moderate, and severe bronchial hyperresponsiveness were $5.9,21.0$, and 30.4 for atopy; $1.9,1.9$, and $\mathbf{7 \cdot 3}$ for early respiratory infection; and $3 \cdot 1,2 \cdot 5$, and $5 \cdot 6$ for a history of parental asthma.
\end{abstract}

Bronchial hyperresponsiveness is recognised as a characteristic feature of asthma. ${ }^{1}$ It has been suggested that the prevalence of bronchial hyperresponsiveness in a community could be used as an objective marker of the prevalence of asthma. ${ }^{2}$ Nevertheless, although there is a fairly close relation between asthma and bronchial hyperresponsiveness, subjects with bronchial hyperresponsiveness do not necessarily have asthma or vice versa. ${ }^{3}$ There are no reports of the prevalence of bronchial hyperresponsiveness in China; the reported prevalence of asthma in China is based on questionnaire surveys. ${ }^{46}$ Questionnaire based figures for the prevalence of asthma may underestimate the true prevalence because some asthmatic subjects, especially children and adolescents, may not have typical wheezing. ${ }^{7}$ In this paper we describe the prevalence of bronchial hyperresponsiveness, diagnosed asthma, and respiratory symptoms in two areas of southern China. We explore the relation between bronchial hyperresponsiveness and several potential risk factors, including atopy, upper respiratory tract infection, family history, early respiratory illnesses, age, sex, and area of residence. We also evaluated the use of peak expiratory flow in the measurement of bronchial hyperresponsiveness in an epidemiological setting.

\section{Methods}

POPULATION

All students aged 11-17 years attending the Hua-Chiao Secondary School in an urban area of Guangzhou (Canton), and the CongHua Secondary School, in a rural area $63 \mathrm{~km}$ from the centre of Guangzhou, were enrolled in the study. There were 1547 students in the urban group and 1564 students in the rural group. Studies were carried out during the winter in December 1987 and January 1988. The mean (SD) temperature during the survey was $15^{\circ}\left(4^{\circ}\right) \mathrm{C}$ in the urban and $14^{\circ}\left(4^{\circ}\right) \mathrm{C}$ in the rural area; humidity during the survey was $60-90 \%$ in the urban and $50-90 \%$ in the rural area. Approval for the study was obtained from the director of the Guangzhou Department of Education and the Guangzhou Health Bureau.

\section{QUESTIONNAIRE}

We used a modified version of the children's questionnaire (78-C) compiled by the American Thoracic Society and the US National Heart and Lung Institute, Division of Lung Diseases. ${ }^{8}$ The questionnaire was translated into Chinese and then translated back into English as a check. A question about nocturnal dry cough was included. Subjects who had wheezing or nocturnal cough were considered to have respiratory symptoms.

\section{LUNG FUNCTION MEASUREMENTS}

Peak expiratory flow (PEF) was measured with a Guangdong peak flow meter. The maximum accepted variation in PEF for repeat blows was $10 \%$ for values of $200-350$ 
$1 / \mathrm{min}$ and $7 \%$ for values of $360-680 \mathrm{l} / \mathrm{min}$. Each measurement was therefore repeated until two successive readings were within 30 $1 / \mathrm{min}$ for the former or $50 \mathrm{l} / \mathrm{min}$ for the latter and the higher of the two values was recorded. The forced vital capacity (FVC) and one second forced expiratory volume $\left(\mathrm{FEV}_{1}\right)$ were measured with a dry spirometer (Vitalograph). Each measurement was repeated until a second value within $100 \mathrm{ml}$ of the maximum $\mathrm{FEV}_{1}$ was obtained and the higher value was recorded. Baseline FVC, $\mathrm{FEV}_{1}$, and PEF values were compared with the predicted values for normal Chinese children and adults. ${ }^{112}$

\section{HISTAMINE INHALATION TEST}

Histamine inhalation tests were carried out by the method of Yan et al, ${ }^{9}$ except that response was measured as change in PEF. ${ }^{10}$ Subjects were taught to inhale from a DeVilbiss No 40 glass nebuliser containing normal saline. PEF was measured before and one minute after an inhalation of normal saline and after each challenge dose of histamine. Four stock solutions $(0.3 \%, 0.6 \%, 2.5 \%$, and $5 \%)$ of histamine were used to give an incremental cumulative dose from 0.03 to $7.8 \mu \mathrm{mol}$ of histamine. The challenge was stopped when the PEF had fallen by $20 \%$ or more or when the highest dose of histamine had been administered. For those undergoing a second histamine inhalation test (see below) both PEF and FEV were measured. Salbutamol by metered dose inhaler was given to aid recovery when necessary. All tests were performed in the afternoon, between 1430 and 1830 hours. A dose-response curve was obtained for each test by plotting PEF or FEV 1 against the logarithmic dose of histamine. The dose of histamine that caused a $20 \%$ fall in PEF or $\mathrm{FEV}_{1}\left(\mathrm{PD}_{20} \mathrm{PEF}\right.$ or $\mathrm{PD}_{20^{-}}$ $\mathrm{FEV}_{1}$ ) was obtained by linear interpolation. $\mathrm{PD}_{20} \mathrm{FEV}_{1}$ from the second test was used to categorise the severity of bronchial hyperresponsiveness.

\section{BRONCHODILATOR RESPONSE}

The bronchodilator response was determined in subjects whose baseline $\mathrm{FEV}_{1}$ was less than $60 \%$ predicted. After the baseline lung function was obtained, $200 \mu \mathrm{g}$ salbutamol was administered from a metered dose aerosol. $\mathrm{FEV}_{1}$ was measured 10 minutes later. An increase of $15 \%$ or more in $\mathrm{FEV}_{1}$ was considered to be a positive bronchodilator response.

\section{SKINPRICK TESTS}

Atopy was assessed using the skinprick test as described by Pepys. ${ }^{13}$ The 13 most common skinprick tests (that is, house dust, Dermatophagoides pteronyssinus, cat fur, horse hair, sheep wool, rabbit fur, dog hair, hay dust, kapok, mixed feathers, maye pollen, Aspergillus fumigatus, and Alternaria tenuis; Bencard, Brentford, Middlesex) were carried out. Histamine $0.5 \%$ was used as a positive control and normal saline as a negative control. Allergens were placed on the volar aspect of the forearm and the skin was pricked through the droplet.
Weal size was recorded after 15 minutes. A mean weal diameter (mean of two diameters perpendicular to each other) more than $2 \mathrm{~mm}$ greater than the saline control was regarded as a positive response. Subjects with one or more positive responses were classified as atopic. An atopy index ${ }^{14}$ was used to relate the degree of atopy to the severity of bronchial hyperresponsiveness. The atopy index is the sum of the number of the four allergen groups (house dust mite, pollen, animal fur, and mould) that gave a positive response plus the size of the largest reaction $(1=<4 \mathrm{~mm}$ and $2=\geqslant 4 \mathrm{~mm})$.

\section{STUDY DESIGN}

Four physicians and three technicians carried out the tests in each area at the same time. Subjects completed the respiratory symptoms questionnaire $^{8}$ under the supervision of medical staff; the questionnaire was then reviewed by a parent of the student. For children under 13 years old the questionnaire was completed by the parents. Histamine inhalation tests were performed by a modification of Yan's method as described by Zhong et al, ${ }^{10}$ the only difference being that a minipeak flow rate meter was used instead of a dry spirometer. Subjects with a peak expiratory flow rate below $60 \%$ predicted underwent spirometry; those with an $\mathrm{FEV}_{1}$ below $60 \%$ predicted then underwent a bronchodilator test. One month later subjects who had had a greater than $20 \%$ fall in PEF during the initial histamine inhalation test underwent a second test, during which both PEF and $\mathrm{FEV}_{1}$ were measured in random order. ${ }^{9}$ Skinprick tests were performed in all subjects with a positive response to the histamine inhalation test and in 656 randomly selected age matched subjects who did not develop bronchoconstriction in response to histamine. Those who were absent from the initial study owing to upper respiratory tract infection completed the questionnaire and underwent a histamine inhalation test three weeks after recovery.

\section{DATA ANALYSIS}

Subjects with a fall in PEF and $\mathrm{FEV}_{1}$ of $20 \%$ or more in both the initial and the repeat study were defined as having bronchial hyperresponsiveness. Subjects were also grouped arbitrarily according to the $\mathrm{PD}_{20} \mathrm{FEV}_{1}$ value $^{15}$ as follows:

\section{Degree of bronchial}

hyperresponsiveness: $P D_{20}$

Severe $\quad<0.1 \mu \mathrm{mol}(0.03 \mathrm{mg})$

Moderate $0.1-0.8 \mu \mathrm{mol}(0.03-0.23 \mathrm{mg})$

Mild $\quad 0.9-3.2 \mu \mathrm{mol}(0.24-0.90 \mathrm{mg})$

Slight $\quad 3.3-7.8 \mu \mathrm{mol}(0.91-2.0 \mathrm{mg})$

Normal None obtained for either PEF or FEV Subjects who had a bronchodilator test because of poor baseline lung function were not included in the analysis or in the figures for prevalence and severity of bronchial hyperresponsiveness.

Asthma was defined by the criteria recommended by the Chinese Thoracic Society ${ }^{16}$ recurrent wheezing, chest tightness, or recurrent dry cough at night relieved sponta- 
neously or after treatment with a bronchodilator. Asthma was defined as current when one of these symptoms had occurred within the last month; subjects with respiratory symptoms or bronchitis before the age of 2 were defined as having early respiratory illness. The prevalence figures given for diagnosed asthma and respiratory symptoms are the cumulative prevalence from birth to the interview time, expressed as percentages of the study sample.

Chi squared analyses of contingency tables were used to determine the associations between various variables. The risk of bronchial hyperresponsiveness $\left(\mathrm{PD}_{20}\right.$ value) in relation to associated factors was expressed as an odds ratio.

\section{Results}

Complete data were obtained from 1515 $(98.0 \%)$ subjects (788 boys, 727 girls) in the urban area and from $1552(99.2 \%)$ subjects (790 boys, 762 girls) in the rural area. Parents of non-responders were interviewed. Three students who were absent from the initial study owing to an upper respiratory tract infection completed the questionnaire and had a histamine inhalation test three weeks after recovery.

At the initial study 176 subjects had a $\mathrm{PD}_{20}$ PEF value of $7.8 \mu \mathrm{mol}$ or less. In the second study, in which both PEF and FEV 1 were measured, 125 of the 176 subjects had a measurable $\mathrm{PD}_{20}$ value for both PEF and FEV and were thus classified as having bronchial hyperresponsiveness. At the first study 61 subjects reported a recent upper respiratory tract infection ( $2 \%$ of 3067$)$, of whom $54(89 \%)$ had bronchial hyperresponsiveness. This is much higher than the proportion in subjects without a respiratory infection $\left(4 \% ; \chi^{2}\right.$ test, $p$ $<0.001)$. Only 15 of the 54 subjects $(28 \%)$, however, had bronchial hyperresponsiveness in the second test $(p<0.05)$.

Baseline lung function in the 125 subjects with bronchial hyperresponsiveness is shown in table 1 . There was a close positive correlation between the $\mathrm{PD}_{20} \mathrm{FEV}_{1}$ and $\mathrm{PD}_{20} \mathrm{PEF}$ in the 125 subjects with bronchial hyperresponsiveness. The regression equation is:

$\ln \left(\mathrm{PD}_{20} \mathrm{PEF}\right)=0.163+0.870 \ln \left(\mathrm{PD}_{20} \mathrm{FEV}_{1}\right)$ $\mathrm{r}=0.857$

Only four subjects received a bronchodilator because their $\mathrm{FEV}_{1}$ was below $60 \%$. All showed an increase in $\mathrm{FEV}_{1}$ of more than $15 \%$.

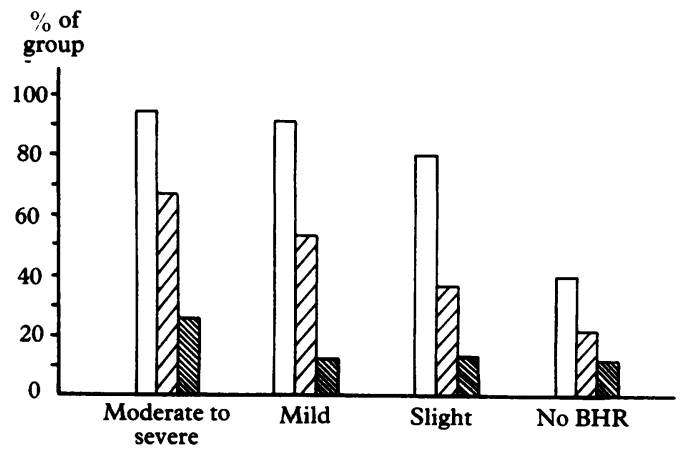

Severity of bronchial hyperresponsiveness (BHR) in relation to atopy, early respiratory illness, and parental asthma. Moderate to severe $B H R-P D_{20}$ $<0.8 \mu \mathrm{m}$; mild $B H R-P D_{20} 0.9-3.2 \mu \mathrm{m}$; slight $B H R-P D_{20} 3 \cdot 3-7 \cdot 8 \mu m$; no $B H R-$ no $P D_{20}$ obtained. $\square$ atopy; early respiratory illness; $\mathbb{Q}$ parental asthma.

The prevalence of bronchial hyperresponsiveness and diagnosed asthma in relation to area of residence, age, and sex is shown in table 2 . The prevalence of bronchial hyperresponsiveness was $4 \cdot 1 \%$ and of asthma $2 \cdot 4 \%$. There was no significant difference between students in urban and rural areas or between boys and girls. The prevalence of bronchial hyperresponsiveness was higher in the 11-12 year old age group $(7.6 \%)$ than in the other two age groups $(\mathrm{p}<0.05)$. There was no significant difference in the prevalence of diagnosed asthma in the three age groups, though the trend was towards a higher prevalence in the younger group.

When the severity of bronchial hyperresponsiveness was classified according to Woolcock ${ }^{15}$ only one subject had severe bronchial hyperresponsiveness; $14(11 \%)$ had moderate, $32(26 \%)$ mild, and $78(62 \%)$ slight bronchial hyperresponsiveness. For the purposes of analysis the severe and moderate groups were combined. The severity of bronchial hyperresponsiveness was closely associated with current asthma, previous asthma, symptoms of wheezing, and nocturnal cough (table $3 ; p<0.01$ in each case). Of the 125 students with bronchial hyperresponsiveness, $59(47 \%)$ were defined as having current asthma and $35(28 \%)$ as having had asthma. None of the 2942 students without a measurable $\mathrm{PD}_{20}$ had current asthma; $0.4 \%$ were defined as having had asthma. The prevalence of bronchial hyperresponsiveness $(4 \cdot 1 \%)$ was much higher than the prevalence of either current $(1.92 \%)$ or previous asthma $(1.6 \%)$. Among the 125 students with bron-

Table 1 Lung function in relation to age and height in 125 students with bronchial hyperresponsiveness (mean (SD) values, with percentages of predicted values in square brackets

\begin{tabular}{|c|c|c|c|c|c|c|c|c|c|c|}
\hline \multirow{2}{*}{$\begin{array}{l}\text { Age } \\
(y)\end{array}$} & \multicolumn{5}{|c|}{ Boys } & \multicolumn{5}{|c|}{ Girls } \\
\hline & $n$ & Height $(\mathrm{cm})$ & $F V C(l)$ & $F E V_{1}(l)$ & $P E F(l / \min )$ & $n$ & Height $(\mathrm{cm})$ & $F V C(l)$ & $F E V_{1}(l)$ & $P E F(l / m i n)$ \\
\hline $11-12$ & 9 & $153(6.4)$ & $\begin{array}{l}2.59(0.45) \\
{[96(15)]}\end{array}$ & $\begin{array}{l}2.29(0.48) \\
{[99(18)]}\end{array}$ & $\begin{array}{l}360(71) \\
{[98(18)]}\end{array}$ & 8 & $151(8 \cdot 2)$ & $\begin{array}{l}2.53(0.46) \\
{[108(18)]}\end{array}$ & $\begin{array}{l}2 \cdot 18(0.44) \\
{[102(20)]}\end{array}$ & $\begin{array}{ll}340 & (42) \\
{[97} & (12)]\end{array}$ \\
\hline $13-15$ & 30 & $159(9 \cdot 5)$ & $\begin{array}{l}3.35(0.59) \\
{[108(17)]}\end{array}$ & $\begin{array}{l}2.89(0.55) \\
{[101(19)]}\end{array}$ & $\begin{array}{l}420(82) \\
{[96(16)]}\end{array}$ & 31 & $154(5.9)$ & $\begin{array}{l}2.90(0.42) \\
{[110(14)]}\end{array}$ & $\begin{array}{l}2.61 \\
{[106}\end{array}$ & $\begin{array}{l}370(40) \\
{[97(11)]}\end{array}$ \\
\hline $16-17$ & 21 & $167(6 \cdot 8)$ & $\begin{array}{l}4.13(0.47) \\
{[103(11)]}\end{array}$ & $\begin{array}{l}3.42(0.48) \\
{[95(14)]}\end{array}$ & $\begin{array}{l}507(67) \\
{[97(13)]}\end{array}$ & 26 & $156(5 \cdot 7)$ & $\begin{array}{l}3 \cdot 16(0 \cdot 50) \\
{[100(15)]}\end{array}$ & $\begin{array}{l}2.66(0.36) \\
{[96(13)]}\end{array}$ & $\begin{array}{l}400(42) \\
{[101(10)]}\end{array}$ \\
\hline
\end{tabular}

FVC_forced vital capacity; $\mathrm{FEV}_{1}$-forced expiratory volume in one second; PEF-peak expiratory flow. 
Table 2 Prevalence (No (\%) of subjects) of bronchial hyperresponsiveness (BHR) and asthma

\begin{tabular}{|c|c|c|c|c|c|}
\hline \multirow[b]{2}{*}{ Total } & \multirow{2}{*}{$\frac{n}{3067}$} & \multicolumn{2}{|c|}{$B H R$} & \multicolumn{2}{|c|}{ Asthma } \\
\hline & & 125 & $(4 \cdot 1)$ & 74 & (2.4) \\
\hline $\begin{array}{c}\text { Area of res } \\
\text { Urban } \\
\text { Rural }\end{array}$ & $\begin{array}{l}: \\
1515 \\
1552\end{array}$ & $\begin{array}{l}59 \\
66\end{array}$ & $\begin{array}{l}(3 \cdot 9) \\
(4 \cdot 3)\end{array}$ & $\begin{array}{l}40 \\
34\end{array}$ & $\begin{array}{l}(2 \cdot 6) \\
(2 \cdot 2)\end{array}$ \\
\hline $\begin{array}{r}\text { Age (y): } \\
11-12 \\
13-15\end{array}$ & $\begin{array}{r}197 \\
1418\end{array}$ & $\begin{array}{l}15 \\
64\end{array}$ & $\begin{array}{l}(7 \cdot 6)^{\star} \\
(4 \cdot 5)\end{array}$ & $\begin{array}{r}8 \\
36\end{array}$ & $\begin{array}{l}(\mathbf{4} \cdot \mathbf{1}) \\
(2 \cdot 5)\end{array}$ \\
\hline $\begin{array}{l}\text { Sex: } \\
\text { Male } \\
\text { Female }\end{array}$ & $\begin{array}{l}1578 \\
1489\end{array}$ & $\begin{array}{l}58 \\
67\end{array}$ & $\begin{array}{l}(3 \cdot 7) \\
(4 \cdot 5)\end{array}$ & $\begin{array}{l}42 \\
32\end{array}$ & $\begin{array}{l}(2 \cdot 7) \\
(2 \cdot 1)\end{array}$ \\
\hline
\end{tabular}

${ }^{\star} \mathrm{p}<0.05$ in the comparison with both older groups.

chial hyperresponsiveness, those without any respiratory symptoms or asthma had a geometric mean (SD) $\mathrm{PD}_{20} \mathrm{FEV}_{1}$ of $6 \cdot 28(2 \cdot 80)$ $\mu \mathrm{mol}$, which was higher than that in subjects with respiratory symptoms or current asthma $\left(\mathrm{PD}_{20} \mathrm{FEV}_{1} 4.11\right.$ (2.42) $\mu \mathrm{mol}$; $\left.\mathrm{p}<0.05\right)$.

The severity of bronchial hyperresponsiveness was correlated with three risk factors:

Table 3 Percentages of students with bronchial hyperresponsiveness (BHR) of varying severity ${ }^{\star}$ with diagnosed asthma and symptoms

\begin{tabular}{|c|c|c|c|c|c|}
\hline & \multicolumn{4}{|c|}{ Severity of $B H R$} & \multirow[b]{2}{*}{$\begin{array}{l}\text { Total } \\
(n=3067)\end{array}$} \\
\hline & $\begin{array}{l}\text { Moderate to } \\
\text { severe } \\
(n=15)\end{array}$ & $\begin{array}{l}\text { Mild } \\
(n=32)\end{array}$ & $\begin{array}{l}\text { Slight } \\
(n=78)\end{array}$ & $\begin{array}{l}\text { None } \\
(n=2942)\end{array}$ & \\
\hline Current asthma & $93 \cdot 3$ & $56 \cdot 3$ & 35.9 & 0 & 1.9 \\
\hline Previous asthma & $73 \cdot 3$ & $37 \cdot 5$ & $15 \cdot 4$ & 0.5 & $1 \cdot 6$ \\
\hline Wheezing & $66 \cdot 7$ & $31 \cdot 3$ & $11 \cdot 5$ & $2 \cdot 0$ & $2 \cdot 8$ \\
\hline Recurrent cough & $40 \cdot 0$ & $43 \cdot 8$ & $24 \cdot 4$ & $7 \cdot 3$ & $8 \cdot 2$ \\
\hline Night cough & $46 \cdot 7$ & $31 \cdot 3$ & $21 \cdot 8$ & $4 \cdot 6$ & $5 \cdot 2$ \\
\hline $\begin{array}{l}\text { Any respiratory } \\
\text { symptom }\end{array}$ & 100 & $56 \cdot 3$ & 35.9 & 11.5 & 12.9 \\
\hline
\end{tabular}

*Degrees of bronchial hyperresponsiveness: moderate to severe: $\mathrm{PD}_{20}<0.8 \mu \mathrm{m}$; mild: $\mathrm{PD}_{20}$ 0.9-3.2 $\mu \mathrm{m}$; slight: $\mathrm{PD}_{20} 3 \cdot 3-7 \cdot 8 \mu \mathrm{m}$; none: no $\mathrm{PD}_{20}$ obtained.

Table 4 Risk of bronchial hyperresponsiveness ( $B H R$ ) in students divided into groups according to their history of atopy, early respiratory illness, and parental asthma (odds ratios with the $95 \%$ confidence limits in parentheses)

\begin{tabular}{|c|c|c|c|c|}
\hline & \multicolumn{3}{|l|}{ Severity of BHR } & \multirow[b]{2}{*}{$p$} \\
\hline & $\begin{array}{l}\text { Moderate to } \\
\text { severe } \\
\left(P D_{20}<0.8 \mu \mathrm{m}\right)\end{array}$ & $\begin{array}{l}\text { Mild } \\
\left(P D_{20} 0.9-3.2 \mu \mathrm{m}\right)\end{array}$ & $\begin{array}{l}\text { Slight } \\
\left(P D_{20} 3 \cdot 3-7 \cdot 8 \mu \mathrm{m}\right)\end{array}$ & \\
\hline Atopy & $30 \cdot 4^{\star} \quad(4 \cdot 0,233 \cdot 0)$ & $21 \cdot 0^{\star}(6 \cdot 3,69 \cdot 8)$ & $5.9 \star \quad(3.5,10.0)$ & $<0.01$ \\
\hline $\begin{array}{l}\text { Early respiratory } \\
\text { illness (ERI) }\end{array}$ & $\begin{array}{lll}7 \cdot 3^{\star} & (2 \cdot 6, & 20 \cdot 7) \\
5 \cdot 6^{\star} & (0 \cdot 7, & 43 \cdot 7)\end{array}$ & $\begin{array}{rr}1.9 & (0.9,4.2) \\
2.5 & (0.3,19.0)\end{array}$ & $\begin{array}{l}1 \cdot 9^{\star}(1 \cdot 2,3 \cdot 2) \\
3 \cdot 1^{\star \star}(1.0,10 \cdot 4)\end{array}$ & $\begin{array}{l}<0.01 \\
<0.01\end{array}$ \\
\hline $\begin{array}{l}\text { Atopy plus ERI or } \\
\text { parental asthma }\end{array}$ & $35 \cdot 5^{\star}(11 \cdot 5,110 \cdot 0)$ & $8 \cdot 1^{\star}(3 \cdot 5,18 \cdot 5)$ & $7 \cdot 9 \star \quad(4 \cdot 3,14 \cdot 4)$ & $<0.01$ \\
\hline
\end{tabular}

${ }^{\star} p<0.01,{ }^{\star \star} p<0.05$ in the comparison with the non-BHR group (the $p$ values in the table refer to the comparison of the whole BHR group with the non-BHR group).

Table 5 Common allergens in students with bronchial hyperresponsiveness (No (\%) of groups)

\begin{tabular}{lllllll}
\hline Group & $n$ & House dust & Mite & Hay dust & Maye pollen & Feathers \\
\hline City & 59 & $33(55.9)$ & $33(55.9)$ & $5(8.4)$ & $9(15 \cdot 2)$ & $10(16.5)$ \\
Rural & 63 & $25(39 \cdot 7)$ & $23(36.5)$ & $23(36.5)$ & $26(41 \cdot 3)$ & $21(33.3)$ \\
p & & $>0.05$ & $<0.05$ & $<0.001$ & $<0.01$ & $<0.05$ \\
\hline
\end{tabular}

^Extract of Dermatophagoides pteronyssinus. atopy ( $p<0.01)$, early respiratory illness $(\mathrm{p}<$ $0.01)$, and parental asthma $(\mathrm{p}<0.05)$ (figure). Comparing the group with normal bronchial responsiveness to the group with moderate or severe bronchial hyperresponsiveness showed an increase in the number of subjects with atopy (from $32 \%$ to $93 \%$ ), of those with early respiratory illness (from $16 \%$ to $60 \%$ ), and of those with a history of parental asthma (from $1.2 \%$ to $6.7 \%$ ). Odds ratios for the severity of bronchial hyperresponsiveness in relation to the three risk factors are shown in table 4. The risk of bronchial hyperresponsiveness was greatest in subjects who were atopic and it increased further in those with atopy plus early respiratory infection and parental asthma.

Results of skinprick tests from 122 subjects with bronchial hyperresponsiveness (table 5) showed that the predominant allergens in the students in the urban area were house dust and house dust mite. Positive reactions to hay dust, maye pollen, and feathers were much higher in the students from the rural area.

There was a positive correlation between the atopy index and the severity of bronchial hyperresponsiveness as measured by the $\mathrm{PD}_{20} \mathrm{FEV}_{1}(\mathrm{r}=0.29, \mathrm{p}<0.01)$.

\section{Discussion}

We modified Yan's method' for histamine inhalation challenge by using peak expiratory flow rate to measure bronchial responsiveness rather than $\mathrm{FEV}_{1}$ and have measured bronchial responsiveness in a large population of children aged 11-17 in two areas of southern China. The prevalence of bronchial hyperresponsiveness in this population was $4 \cdot 1 \%$. The prevalence of bronchial hyperresponsiveness was not affected by sex or area of residence, but was slightly higher in younger children. Atopy was the most significant risk factor for bronchial hyperresponsiveness. The prevalence of diagnosed asthma was $2 \cdot 4 \%$. The severity of bronchial hyperresponsiveness was closely but not completely associated with respiratory symptoms and a diagnosis of asthma.

The study population was an unbiased sample with a very high rate of compliance; 3067 out of 3111 students in the two secondary schools completed the survey $(98.6 \%)$. Reasons for non-response were established by interview with the parents of absent students to determine whether it was due to respiratory illness. The survey was carried out simultaneously in urban and rural schools, during the winter months to minimise seasonal effects.

Measures were taken to ensure the reliability of the data collection methods. All staff members taking part in the study received one week's technical training, including the correct use of the peak flow meter and DeVilbiss nebuliser. The GD peak flow meter (Guangzhou Institute of Medical Instrumentation, Guangzhou, Guangdong, China) was used to measure lung function in the initial study. We have shown previously ${ }^{10}$ that there is a close linear correlation between change in $\mathrm{PEF}$ and change in $\mathrm{FEV}_{1}$ during the histamine inhalation test, and a close correlation between 
$\mathrm{PD}_{20} \mathrm{FEV}_{1}$ and $\mathrm{PD}_{20} \mathrm{PEF}$ was found in the present study. Being simple, cheap, and easy to use, the peak flow meter is a useful tool for measuring response in histamine inhalation tests in large populations and gives results similar to those obtained with the $\mathrm{FEV}_{1}$.

Bronchial hyperresponsiveness was defined on the basis of a reproducible response to two histamine inhalation tests. Students with a fall in PEF of $20 \%$ or more with the first histamine challenge received a second histamine challenge test four weeks later. Only those who had a fall in both PEF and FEV 1 of $20 \%$ in the second test were considered to have bronchial responsiveness. Of the 176 students who had a fall in PEF of $20 \%$ in the initial test, 125 had a fall in both PEF and FEV of $20 \%$ in the second test. Mean baseline FVC, $\mathrm{FEV}_{1}$, and PEF values in these 125 children (table 1) were within the predicted range for Chinese children. ${ }^{11}{ }^{12}$ Of 51 children without a $20 \%$ fall in $\mathrm{FEV}_{1}$ and PEF in response to histamine in the second study, 39 had had an upper respiratory tract infection within two weeks of the initial study. In contrast to the results of Peat $e t$ al, ${ }^{14}$ who found no relation between recent upper respiratory tract infection and bronchial responsiveness, our data suggest that an upper respiratory tract infection increased bronchial responsiveness. Of the 61 students with an upper respiratory tract infection at the first visit, 54 had bronchial hyperresponsiveness, compared with 15 at the second visit. Burney et $a l^{17}$ and Josephs et $a l^{18}$ have shown that bronchial responsiveness will vary within subjects if measured on more than one occasion. The present criteria may lead to an underestimation of the prevalence of bronchial hyperresponsiveness in relation to the results of other studies, but our study has shown that upper respiratory tract infection is an important factor interfering with prevalence figures. To reduce the number of false measurements of bronchial hyperresponsiveness, the "natural" bronchial responsiveness of those subjects was determined by repeating the histamine challenge at least three weeks after the upper respiratory tract infection. ${ }^{19}$

The prevalence of bronchial hyperresponsiveness in our population was $4.1 \%$, which is considerably lower than that reported in children by Salome et al $(17.9 \%),{ }^{3}$ Sears et al $(25 \%),{ }^{20}$ and Weiss et al $(21 \%) .{ }^{21}$ The methods used to measure and define bronchial hyperresponsiveness differed, however, though there may also be differences due to race, environment, and age. The prevalence measurements in the previous studies were obtained in children aged 8-11 years. In our study the prevalence of bronchial hyperresponsiveness was higher in the $11-12$ year group $(7 \cdot 6 \%)$ than in those aged 13-15 $(4 \cdot 2 \%)$ and $16-17$ years $(3.2 \%)$. The prevalence of bronchial hyperresponsiveness may be higher still in the 8-11 year age group in southern China.

The prevalence of diagnosed asthma in our population was $2 \cdot 4 \%$, which is much lower than that found by Salome et al $(12 \cdot 8 \%)^{3}$ and Dodge and Burrows $(6.6 \%)^{22}$ but similar to that found by Lee et $a l^{23}$ and Alanko. ${ }^{24}$ The prevalence in the 11-12,13-15, and 16-17 year age groups $(4 \cdot 1 \%, 2 \cdot 5 \%$, and $2 \cdot 1 \%)$ did not differ significantly, possibly owing to the small sample size (197) in the 11-12 year age group. There was a trend towards a decreased prevalence of both bronchial hyperresponsiveness and asthma in the older groups, as noted by others. ${ }^{25}$

The severity of bronchial hyperresponsiveness was closely associated with the prevalence of current or previous asthma, wheezing, and night cough. Among the 125 students with bronchial hyperresponsiveness mean $\mathrm{PD}_{20}$ $\mathrm{FEV}_{1}$ was lower in those with any respiratory symptom or diagnosed asthma. Sixty six out of 125 students with bronchial hyperresponsiveness $(53 \%)$ were symptom free, however, and 12 students previously diagnosed by a doctor as having bronchial asthma had normal bronchial responsiveness. Thus we agree with the comment of Salome et $a l^{3}$ that there is an incomplete association between bronchial hyperresponsiveness and diagnosed asthma. Possibly those with symptom free bronchial hyperresponsiveness are at higher risk for the development of asthma, but there is so far no evidence to support this.

The prevalence of bronchial hyperresponsiveness and diagnosed asthma did not differ between the urban and rural groups, or between boys and girls. Although the air concentrations of suspended particles (mean (SD) $226(120) \mu \mathrm{g} / \mathrm{m}^{3}$ ) and sulphur dioxide (78 (58) $\left.\mu \mathrm{g} / \mathrm{m}^{3}\right)$ in the urban resident area of Guangzhou were slightly higher than those in the rural Conghua area (153 (92) $\mu \mathrm{g} / \mathrm{m}^{3}$ and 35 (30) $\left.\mu \mathrm{g} / \mathrm{m}^{3}\right),{ }^{26}$ the outdoor temperature, humidity, and lifestyle are similar in the two areas. The prevalence of asthma and bronchial hyperresponsiveness also did not differ between boys and girls. Coultas and Samet, by contrast, found a higher prevalence of asthma in boys than girls. ${ }^{27}$

Atopy was the most important risk factor associated with bronchial hyperresponsiveness. Welty $e t a^{28}$ and Woolcock et al ${ }^{29}$ failed to find any correlation between atopy and bronchial hyperresponsiveness in their adult population surveys. In the present study, however, more than $80 \%$ of subjects with bronchial hyperresponsiveness were atopic-a very much higher proportion $(p<0.001)$ than in those with no bronchial hyperresponsiveness $(31 \cdot 5 \%)$. Odds ratios for atopy increased from 5.9 to 30.4 in those with slight to moderate (and severe) bronchial hyperresponsiveness. In addition, the severity of bronchial hyperresponsiveness was correlated with the atopy index, as in the study of Peat et al. ${ }^{30}$ Seventeen of the 125 subjects with bronchial hyperresponsiveness $(13.6 \%)$, however, had negative skin test responses.

Early respiratory infection was also a risk factor for bronchial hyperresponsiveness, the odds ratios being 1:9 for those with slight and $7 \cdot 3$ for those with moderate bronchial hyperresponsiveness. This result is in accordance with the data of Gurwitz et al..$^{31}$ The odds ratios for a parental history of asthma ranged from $3 \cdot 1$ in those with slight to 5.6 in those with 
moderate and severe bronchial hyperresponsiveness, in keeping with the data of Peat $e t$ al. Inherited factors may play a part in the development of asthma ${ }^{32}$ and may be concerned in the development of bronchial hyperresponsiveness. The risk of bronchial hyperresponsiveness was further increased in those with atopy in addition to early respiratory infection or parental asthma (odds ratios ranging from 7.9 in those with slight to 35 in those with moderate and severe bronchial hyperresponsiveness.

The allergen skinprick tests showed differences in responses depending on the area of residence. Students in the urban area were more likely to have a positive response to house dust mite allergen than those in the rural area, whereas a positive response to hay dust, feathers, and pollen were much more common in the rural area. These differences probably reflect differences in the type of aeroallegen in the two aras. Students reactive to both mite and pollen allergens had an increased risk of bronchial hyperresponsiveness.

Thus a modified Yan histamine inhalation test has been shown to be simple to use for measuring bronchial responsiveness in a large population. In 11-17 year old students in southern China the prevalence of bronchial hyperresponsiveness was increased in younger students. The severity of bronchial hyperresponsiveness was closely associated with diagnosed asthma, atopy, early respiratory infection, and parental asthma; about half of these students with bronchial hyperresponsiveness were symptom free.

We wish to thank Dr K Y Yan for his advice on the paper; Drs Y F Li, S Y Yao, A P Luo, S S Yao, and X Y Wu for gathering the Yata; Mr J S Liang for typing; and Ms S C Gao for her assistance in the analysis of statistical data.

1 Boushey HA, Holtzman MJ, Sheller JR, Nadel JA Bronchial hyperreactivity. Am Rev Respir Dis 1980; 121:389-413.

2 Woolcock AJ. Test of airway responsiveness in epidemiology. In: Hargreave FE, Woolcock AJ, eds. Airway responsiveness: measurement and interpretation. Mississauga, Ontario: Astra, 1985:136-40.

3 Salome CM, Peat JK, Britton WJ, Woolcock AJ. Bronchial Hyperresponsiveness in two populations of Australian school children. I. Relation to respiratory symptoms and diagnosed asthma. Clin Allergy 1987;17:271-81.

4 Lin AY, Liu JB, Wang LR, et al. Prevalence of bronchial asthma in 250,000 population in Changsha area. Chinese $J$ Tuberc Respir Dis 1987;10:248.

$5 \mathrm{Chu}$ JL, Chen SJ, Chu HR, et al. Prevalence of bronchial asthma in 140,000 population in Shanghai city and suburb of Jia Shen. Chinese J Tuberc Respir Dis 1981;4:329-32.

6 Research Group of Asthma Prevalence. A primary report of the prevalence of bronchial asthma in Southern China. Chinese J Tuberc Respir Dis 1986;9:217-20.

7 Zhang YG, Chen RC, Yu MJ, Zhong NS. Bronchial asthma with chronic cough as the chief manifestation. Chinese Tuberc Respir Dis 1986;9:321-4.

8 Ferris BG. Epidemiology standardization project. II
Recommended respiratory disease questionnaires for use with adults and children in epidemiological research. 2Children's questionnaire (ATS-DLD-78-C). Am Rev Respir Dis 1978;118:36-53.

9 Yan K, Salome CM, Woolcock AJ. Rapid method for measurement of bronchial hyperresponsiveness. Thorax 1983;38:760-5.

10 Zhong NS, Li YF, Zhang YC, Ou-yang M, Luo DF. A simplified bronchial provocation test. Chinese J Tuberc Respir Dis 1987;10:293-5.

11 Lam KK, Pang SC, Allen GL, et al. Predictive nomograms for forced expiratory volume, forced vital capacity, and peak expiratory flow rate, in Chinese adults and children. Br J Dis Chest 1983;77:390-6.

12 Zhong NS, Zhang YG, Yu MJ, et al. Peak expiratory flow rate in normal subjects and patients with bronchial asthma. Chinese J Tuberc Respir Dis 1985;8:138-41.

13 Pepys J. Type of allergic reaction. Clin Allergy 1973;3: 491-509.

14 Peat JK, Britton WJ, Salome CM, Woolcock AJ. Bronchial hyperresponsiveness in two populations of Australian school children. III. Effect of exposure to environmental allergens. Clin Allergy 1987;17:291-300.

15 Woolcock A. Bronchial hyperresponsiveness: the key to long term control. J Respir Dis 1987(May);suppl:510-3.

16 Chinese Thoracic Society. Criteria of the diagnosis and staging of bronchial asthma and the assessment of therapeutic efficacy. Chinese J Tuberc Respir Dis 1984; 7:186-7.

17 Burney PGJ, Britton JR, Chinn S, et al. Descriptive epidemiology of bronchial reactivity in an adult population: results from a community study. Thorax 1987;42: 38-44.

18 Josephs LK, Gregg I, Mullee MA, Holgate ST. Nonspecific bronchial reactivity and its relationship to the clinical expression of asthma. Am Rev Respir Dis 1989;140:350-7.

19 Weeke B, Madsen F, Frolund L. Reproducibility of challenge tests at different times. Chest 1987;91 (suppl):83-8S.

20 Sears MR, Jones DT, Holdaway MD, et al. Prevalence of bronchial reactivity to inhaled methacholine in New Zealand children. Thorax 1986;41:283-9.

21 Weiss ST, Tager IB, Weiss JW, Munoz A, Speiser FE, Ingram RH. Airways responsiveness in a population sample of adults and children. Am Rev Respir Dis 1984; 129:898-902.

22 Dodge PR, Burrows $B$. The prevalence and incidence of asthma and asthma-like symptoms in general population sample. Am Rev Respir Dis 1980;122:567-75.

23 Lee DA, Winslow NR, Speight ANP, Hey EH. Prevalence and spectrum of asthma in childhood. $\mathrm{Br}$ Med $\mathrm{J}$ 1983;286: 1253-6.

24 Alanko $\mathrm{K}$. The prevalence of asthma in a Finnish rural population. Scand J Respir Dis 1970;76:1-64

$25 \mathrm{McNicol} \mathrm{KN}$, Williams HB. Spectrum of asthma in children. I. Clinical and physiological components. Br Med J 1973;iv:7-11.

26 Huang LF. Air pollution in city area and Cong-hua area of Guangzhou (1986-1987). In: Du YS, ed. Proceedings of the Second Conference on Lung Cancer. Vol 2. Guangzhou: Guangzhou Scientific and Technical Association, 1987:107-10.

27 Coultas DB, Samet JM. Epidemiology and natural history of childhood asthma. In: Tinkelman DG, Faltiers CJ, Naspitz CK, eds. Childhood asthma: pathophysiology and treatment. New York: Dekker, 1987:131-58.

28 Welty CW, Weiss ST, Tager IB, et al. The relationship of airways responsiveness to cold air, cigarette smoking, and atopy to respiratory symptoms and pulmonary function in adults. Am Rev Respir Dis 1984;130:198-203.

29 Woolcock A, Colman MH, Jones MW. Atopy and bronchial reactivity in Australian and Melanesian populations. Clin Allergy 1978;8:155-64.

30 Peat JK, Britton WJ, Salome CM, Woolcock AJ. Bronchial hyperresponsiveness in two populations of Australian school children. II. Relative importance of associated factors. Clin Allergy 1987;17:283-90.

31 Gurwitz D, Mindorff C, Levison H. Increased incidence of bronchial reactivity in children with a history of bronchiolitis. J Paediatr 1981;98:551-5.

32 Sibbald B, Turner-Warwick $M$. Factors influencing the prevalence of asthma among first degree relatives of extrinsic and intrinsic asthmatics. Thorax 1979;34:332-7. 